San Jose State University

SJSU ScholarWorks

Master's Theses

Master's Theses and Graduate Research

1991

\title{
The relationship between the first-born child's gender and parents' selection of infant room contents
}

Diane Rose Vincent

San Jose State University

Follow this and additional works at: https://scholarworks.sjsu.edu/etd_theses

\section{Recommended Citation}

Vincent, Diane Rose, "The relationship between the first-born child's gender and parents' selection of infant room contents" (1991). Master's Theses. 273.

DOI: https://doi.org/10.31979/etd.gcj9-q6sm

https://scholarworks.sjsu.edu/etd_theses/273

This Thesis is brought to you for free and open access by the Master's Theses and Graduate Research at SJSU ScholarWorks. It has been accepted for inclusion in Master's Theses by an authorized administrator of SJSU ScholarWorks. For more information, please contact scholarworks@sjsu.edu. 


\section{INFORMATION TO USERS}

This manuscript has been reproduced from the microfilm master. UMI films the text directly from the original or copy submitted. Thus, some thesis and dissertation copies are in typewriter face, while others may be from any type of computer printer.

The quality of this reproduction is dependent upon the quality of the copy submitted. Broken or indistinct print, colored or poor quality illustrations and photographs, print bleedthrough, substandard margins, and improper alignment can adversely affect reproduction.

In the unlikely event that the author did not send UMI a complete manuscript and there are missing pages, these will be noted. Also, if unauthorized copyright material had to be removed, a note will indicate the deletion.

Oversize materials (e.g., maps, drawings, charts) are reproduced by sectioning the original, beginning at the upper left-hand corner and continuing from left to right in equal sections with small overlaps. Each original is aiso photographed in one exposure and is included in reduced form at the back of the book.

Photographs included in the original manuscript have been reproduced xerographically in this copy. Higher quality $6 "$ x 9 " black and white photographic prints are available for any photographs or illustrations appearing in this copy for an additional charge. Contact UMI directly to order.

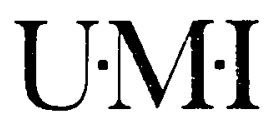

University Microfilms International

A Bell \& Howell Information Company 

Order Number 1347188

The relationship between the first-born child's gender and parents' selection of infant room contents

Vincent, Diane Rose, M.A.

San Jose State University, 1991 


$\because \ldots+\ldots \ldots+\ldots$




\title{
THE RELATIONSHIP BETWEEN THE FIRST-BDRN CHILD'S GENDER AND PARENTS' SELECTION OF INFANT ROOM CONTENTS
}

\author{
A Thesis \\ Presented to \\ the Faculty of the Department of Psychology \\ San Jose State University
}

In Partial Fulfillment

of the Requirements for the Degree

Master of Arts

by

Diane Rose Vincent

December, 1991 
APPROVED FOR THE DEPARTMENT OF PSYCHOLOGY

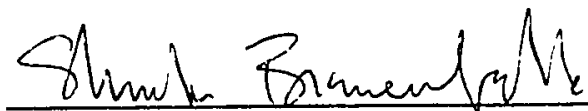

Sheila Bienenfeld, Ph.D., San Jose State University Faculty, Chairperson

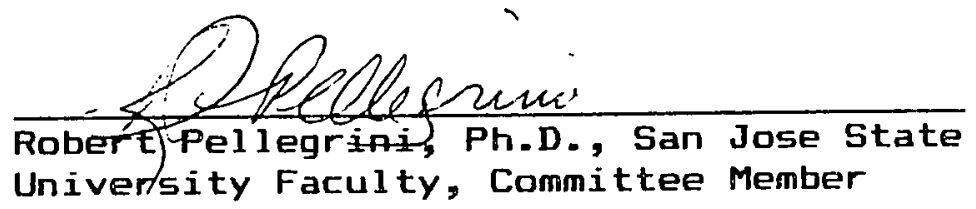
Roher \&. Oogperft. Robert Cooper, Ph.D., Sab Jose State University Faculty, Committee Member

APPROVED FOR THE UNIVERSITY

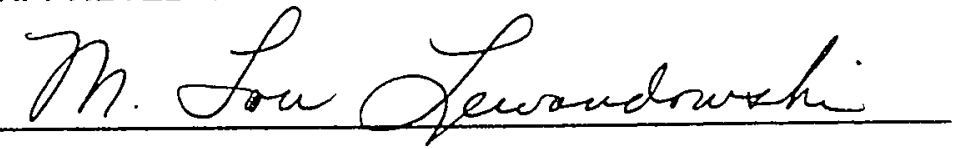


ABSTRACT

THE RELATIONSHIP BETWEEN THE FIRST-BORN CHILD'S GENDER AND PARENTS" SELECTION OF INFANT ROOM CONTENTS by Diane Rose Vincent

Thirty sets of parents of six to nine month-old, first-born infants participated in a study investigating the relationship between parental attitudes and parental behaviors, regarding gender-stereotyping. Attitudinal measures included mothers' and fathers ${ }^{\circ}$ views on the appropriateness of traditionally masculine and feminine activities for boys and girls. Behavioral measures were based on the amount of traditional feninine and masculine items in their infants" rooms. Both parents" attitudes toward boys and girls, combined and individually, were found to be positively related to items chosen for the girls' rooms. There was no significant relationship discovered between either of the parents views and the environments in the boys' rooms. The results are discussed in terms of their implications for the gender-role socialization of young children. 
TABLE OF CONTENTS

SECTION

PAGE

INTRDDUCTIDN.............................

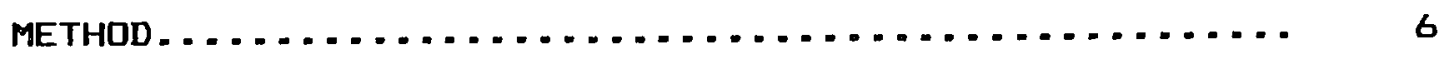

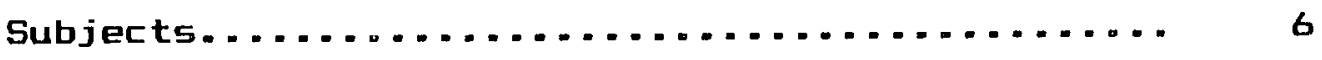

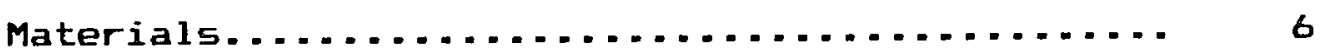

Design and Procedure.....................

RESULTS. . . . . . . . . . . . . . . . . . . . . . . . 11

Discussion. ............................... 16

REFERENCES. . . . . . . . . . . . . . . . . . . . . .

APPENCICES. . . . . . . . . . . . . . . . . . . . . . . . . . 24

Appendix A. Signed Approval Forms............. 24

Appendix B. Recruitment Script.............. 26

Appendix C. Classification of Items Checklist... 27

Appendix D. Activities Questionnaire.......... 28

Appendix E. Debriefing...................... 29 


\section{LIST DF TABLES}

TABLE

PAGE

1. Correlations Between Parent-Behaviors and

Parent-Attitudes in Children's Rooms............ 13

2. Person Designated as Primary Selector of

Items for Children's Rooms................... 15 
Parental Selections

1

The Relationship Between the First-Born Child's Gender and Parents. Selection of Infant Room Contents Diane Rose Vincent

San Jose State University

Running Head: PARENTAL SELECTIONS BASED ON GENDER OF CHILD 
Parental Selections

\begin{abstract}
Thirty sets of parents of six to nine month-old, first-born infants participated in a study investigating the relationship between parental attitudes and parental behaviors, regarding gender-stereotyping. Attitudinal measures included mothers' and fathers' views on the appropriateness of traditionally masculine and feminine activities for boys and girls. Behavioral measures were based on the amount of traditional feminine and masculine items in their infants' rooms. Both parents' attitudes toward boys and girls, combined and individually, were found to be positively related to items chosen for the girls' rooms. There was no significant relationship discovered between either of the parents views and the enviranments in the boys" rooms. The results are discussed in terms of their implications for the gender-role socialization of young children.
\end{abstract}


Parental Selections

The Relationship of the First-Born Child's Gender

On Parents' Selection of Infant Room Contents

Much evidence has shown that adults are predisposed to respond differently to boys and girls, and therefore play a substantial role in shaping gender-related differences in the child's behavior, an influence which begins in infancy (Seavey, Katz, \& Zalk, 1975; Smith \& Lloyd, 1978; Will, Self, \& Datan, 1976). Some researchers think that adult perceptions and reactions are determined to a large extent by the child's behavior (Bell \& Carver, 1980; Fagot, 1974), whereas athers have found mothers' responses to be based more on their own predispositions than the infants' cues (Will et al., 1976). Evidence suggests that parents are not fully aware of the differential contingencies they use to socialize their young children. Parents view and treat their newborn children differently, depending on the gender of the child. Girls are described as soft, fine-featured, little, awkward, and weak. Boys are rated as well-coordinated, large-featured, firm, big, and strong (Fagot, 1978) -

Play with gender-typed toys is related to development of differential cognitive (verbal/spatial) or social (nurturance/aggression) skills in girls and boys (Miller, 1987). Play with stereotypical boys' toys 
(especially blocks) has been related to higher scores of spatial ability, whereas play with stereotypical girls' toys has been related to higher verbal scores lconnor \& Serbin, 1977). A number of investigators have shown that by age three, girls and boys learn gender-typed discrimination and display a preference for toys and activities which adults consider gender-appropriate (Barry \& Barry, 1976; Fling \& Manosevitz, 1972; Nadelmen, 1974).

Rheingold and Cook (1975) conducted a study, which proposed that how parents furnish the rooms of their sons and daughters, including the toys they supply, provides an index to their ideas about appropriateness by gender. Because items in the roums offer children different experiences, the contents may instruct boys and girls in what is proper for their gender. Therefore, the environment is seen as a subtle cue of differential treatment that can encourage gender-stereotyped behavior in children. Boys are provided objects that encourage activities directed away from the home (i.e., sports, vehicles, military) and girls are provided objects that encourage activities directed toward the home (i.e., dolls, soft toys, dance).

Although Rheingold \& Cook (1975) examined the gender-preferred behaviors of parents, they merely assumed these actions were exemplary of their gender-stereotypical 
Parental Selections

views. Fagot (1974, 1978) and Smith \& Daglish (1977)

studied parents' gender-preferred behaviors, via

observations of child/parent interactions, followed by

questionnaires designed to indicate levels of

gender-stereotypical beliefs.

The present study is a modification, partial

replication, and extension of these three studies. Parents'

gender-preferred behaviors were measured via room content

classification lists. Parents' stereotypical gender-role

views were measured by questionnaires. The purpose of this

study was to compare the relationship between parents'

child-related behaviors and their child-related attitudes.

Questions of primary interest were: "What are parents"

views toward gender-role socialization?" and "Are these

attitudes being reflected in parents' behaviors toward their

children?" It was hypothesized that parents who maintain

traditional gender-role attitudes will furnish their

children's rooms in a traditional manner, and parents who

have non-traditional gender-role attitudes will furnish

their children's rooms in a non-traditional style. This was

expected to be reflected by a positive correlation of

attitude and behavior scores. 
Parental Selections

6

Method

\section{Subjects}

Parents of young children were obtained from the record of births in San Mateo and Santa Clara Counties and referrals. Parents syere contacted by phone and asked to participate in the study, until there were thirty families. These families consisted of a mother, a father, and their first-born child. The purpose of the study was explained to the parents in terms of interest in children's home environments (see Appendix B). Possible risks to subjects were no greater than encountered in daily life. The children were fifieen boys and fifteen girls, with their own rooms, between $s i x$ and nine months of age. The first-born status and young age of the children were expected to increase the probability that any detected differences in gender-role behaviors and stereotypes would originate from the parents.

Materials

The gender-stereotypical items of the infants' rooms (i.e., toys, furnishings) were recorded on a classification checklist similar to the system used by Rheingold \& Cook (1975). Selected items matched activities that evidenced significance for males or females in studies by Fagot (1974, 1978) and Smith and Daglish (1977). The 
Parental Selections

classification of items checklist (see Appendix C) was comprised of: female and baby dolls, soft toys and stuffed animals, female stuffed animals, and traditional female themes on furnishings and toys (i.e., dance, domestic, passive, hearts, flowers, ruffles, pink) for gender-typed girls' itens; blocks, objects to manipulate, transportation toys, male stuffed animals, and traditional male themes in furnishings and toys (i.e., sports, aggression, active, animals, vehicles, blue) for gender-tyied boys' items. A Polaroid Impulse with color film was used to photograph the room contents.

Each parent individually rated a set of twelve behaviors, derived from the questionnaire used originally by Fagot (1974, 1978). The selected questions included activities that were found to be significantly stereotyped in either female or male gender-role orientation, in two or more of the following test categaries: behavior of child, parent reaction to child behavior, and parent view of child behavior (Fagot, 1974, 1978; Smith \& Daglish, 1977). The tweive resultant child activities (see Appendix D) were: block play, (M); play with transportation toys, (M); doll play, (F); manipulating objects, (M); play with soft toys/stuffed animals, (F); dance, (F); ask for help, (F); dress-up, (F); "rough-and-tumble" play, (M); aggression, 
(M); running, jumping, and climbing, (M); and help adult, $(F)$.

Design and Procedure

The survey was carried out between March and August

1990. After the observer answered all questions and explained the procedure, when agreeable, both parents signed a consent form. The contents of the rooms were recorded in their entirety. In addition, color photographs were taken of the rooms, to supplement the written lists. Children's toys and objects located elsewhere in the homes were not recorded. But it was noted how many of the infants rooms did not contain the major part of the children's items.

After the observations were completed, parents were independently asked to rate each of the twelve child behaviors on the gender-stereotypical view questionnaire as to the degree of appropriateness for girls and boys. The activities were ordered on the questionnaire by random selection. A final question inquired as to who chooses the majority of items for the children's rooms; the mother, father, both, or other. In debriefing, when observations and questionnaires were completed, a full explanation regarding gender-role differences and the infants bedroom environment was given (see Appendix E). 
Parental Selections

After collecting all of the information from the thirty homes, the items in the rooms were rated for gender-stereotyping. Since the researcher had been in contact with the parents, and was not blind to the purpose of the study, a rater who was blind to the characteristics of the parents and to the purpose was recruited to do the rating. The blind rater coded the items determined to be gender-stereatypical on the classification list, by viewing photographs and complete lists of items in the bedrooms. In order to further provide for reliability on the coding, inter-rater reliability was calculated for the rating of six of the rooms by the researcher and the blind rater. The agreement between the codings of the two raters was significant.

The data for the gender-preferred behaviors was the percentage of gender-stereotypical items in the children's rooms. Traditional boys' items were counted as positive, while traditional girls' items were summed as negative. The total number of all items in the infants' rooms was noted. Scores were computed by dividing the sum of positive and negative class 1 ist items by the total of all items in each of the children's rooms. On the gender-stereotype behavior continuum: in the girls' rooms, parents' traditional behavior approached -1, egalitarian behavior approached 0 , 
Parental Selections

and non-traditional behavior approached +1; in the boys' rooms, parents' traditional behavior approached +1 , egalitarian behavior approached 0 , and non-traditional behavior approached -1 .

On the gender-stereotype attitude questionnaire, activities were rated on a scale of appropriateness for each sex as: O, never appropriate; 1, usually not appropriate; 2, occasionally appropriate; 3, often appropriate; 4, almost always appropriate; and 5, always appropriate. Scores were calculated by summing up the total number of positive male-rated activities and negative female-rated activities. A separate score was computed for mothers regarding girls, mothers regarding boys, fathers regarding girls, fathers regarding boys, both parents regarding girls, and both parents regarding boys. On the gender-stereotype attitude continuum: for girls, parents' traditional attitudes were negative, egalitarian attitudes approached 0 , and non-traditional attitudes were positive; for boys, parents' traditional attitudes were positive, egalitarian attitudes approached $O$, and non-traditional attitudes were negative.

In order to evaluate the magnitude of the quantity of traditional behavior for girls' rooms on a comparable basis with the traditional behavior for boys' rooms, the final 
negative and positive scores in the girls' rooms were reversed. As a result, in both boys' and girls' roams, parents' traditional behavior approached +1 , egalitarian behavior approached 0 , and non-traditional behavior approached -1 .

Similar to the adjusted scoring of behavior for the girls' rooms, for the purpose of evaluating the magnitude of the quantity of traditional attitude. by both parents toward both boys and girls on a comparable basis, the final negative and positive scores for girls were reversed. The sum total of attitudes of mothers regarding girls, mothers regarding boys, fathers regarding girls, and fathers regarding boys was then calculated.

\section{Results}

In order to determine the degree of relationship between parents' gencier-preferred behavior (as demonstrated by the choice of items for their children's rooms) and parental gender-role views (as revealed by the questionnaires), the sum total of both parents' gender attitudes towards boys and girls was correlated with the gender-behavior scare for girls' rooms and for boys' rooms. A problem with the study is that the small sample size measures only moderate and strong correlations as significant. 
Parental Selections

Then the six individual parent-attitude scores in the boys' roans were correlated with the parent-behavior scores in the boys' rooms. Likewise, the six individual

parent-attitude scores in the girls' rooms were correlated with the parent-behavior scores in the girls' rooms.

The comparison between both parents' attitudes toward both sexes of children and the parents' behavior in the boys ${ }^{\circ}$ rooms indicated no relationship ( $r=.01, \mathrm{p}^{=.98)}$. The correlation of both parents views toward both boys and girls and items chosen in the girls' rooms was not significant $\left(\mathrm{p}^{=-15}\right)$, but at $\mathrm{r}=.39$ suggested there may be a relationship. In the individual analyses, both parents views toward boys was most highly related to items chosen in the girls. rooms $(r=.75, \underline{p}=.001)$. The other significant relationship was between fathers' views toward boys and items chosen in the girls' rooms $\left(r=.64, \mathrm{e}^{=}=01\right)$. Although not reaching the .05 level of significance, both parents' views toward girls appeared to be related to items chosen in the girls rooms $\left(r=.49, \mathrm{~g}^{=.06)}\right.$. There was a weaker non-significant correlation between fathers views toward girls and items chasen in the girls' rooms $\left(r=.44, \mathrm{~g}^{=}=10\right)$, and mothers views toward girls and items chosen in the boys' rooms $(r=.38, p=.17)$. Table 1 presents the correlations for these analyses. 
Parental Selections

TABLE 1

Correlations Between Parent-Behaviors and Parent-Attitudes in Children's Rooms

Girls' Rooms Boys' Rooms

Mother/Girl

$\underline{r}=.29 \quad \mathrm{p}=.30$

$\underline{r}=.38 \quad \mathrm{Q}=.17$

Mother/Boy

$r=.35 \quad p=.21$

$r=.09 \quad \mathrm{p}=.75$

Father/Girl

$r=.44 \quad \mathrm{p}=.10$

$r=-.30 p=.28$

Father/Boy

$r=.64 \quad p=.01$

$r=.15 \quad Q=.59$

Both/Girl

$r=.49 \quad p=.06$

$r=.19 \quad \mathrm{Q}=.49$

Both/Boy

$r=.75 \quad \mathrm{Q}=.001$

$r=.13 \quad p^{=.65}$

Both/Both

$\underline{r}=.39 \quad \mathrm{p}=.15$

$r=.01 \quad p=.98$ 
In the fifteen girls' rooms, ten sets of parents agreed that the mother had chosen the majority of items, three sets of parents agreed that they had both chosen most of the items, one father stated that both parents had selected items while the mother chose herself as the primary selector, and one mother answered that both parents had selected items while the father chose the mother as the primary selector. These totals indicate that the mothers did the majority of choosing items for the girls' rooms. In che fifteen boys ${ }^{\circ}$ rooms, four sets of parents agreed that the mother had chosen the majority of items, four sets of parents agreed that most items were chosen by both parents, four fathers stated that both parents had selected items while the mother chose herself as the primary selector, and three mothers answered that both parents had selected items while the father chose the mother as the primary selector. According to these groupings, it appears that the fathers participated to some extent, along with the mothers, in choosing the majority of items for the boys' rooms. Table 2 presents the tatals of who the parents believe chose most of the items in the children's rooms. None of the parents, in either the boys' or the girls' rooms, indicated that the father or any other person had selected the majority of items. Most of the parents 
Parental Selections

TABLE 2

Person Designated as Primary Selector of Items for

Children's Rooms

15 Boys' Rooms

15 Girls' Rooms

\begin{tabular}{lcc}
\hline $\begin{array}{l}\text { Both Parents } \\
\text { Say Mother }\end{array}$ & 4 & 10 \\
\hline $\begin{array}{l}\text { Both Parents } \\
\text { Say Both }\end{array}$ & 4 & 3 \\
\hline $\begin{array}{l}\text { Father Says Both } \\
\text { Mother Says Mother }\end{array}$ & 4 & 1 \\
\hline $\begin{array}{l}\text { Mother Says Both } \\
\text { Father Says Mother }\end{array}$ & 3 & 1 \\
\hline
\end{tabular}


mentioned that many of the items in their children's rooms had been gifts.

Dut of the fifteen girls' rooms, nine rooms contained most of the children's items, while six homes had many of the infants items outside of the rooms. Out of the fifteen boys' rooms, eight rooms contained most of the infants' items, while seven homes had many of the children's items outside of the rooms. Five of the six girls' homes, with many items outside of the rooms, rated as highly negative (traditional, feminine). Three of the seven boys' homes, with many items outside of the rooms, rated as negative (non-traditional, feminine). In the cases of homes where many of the items were outside the children's rooms, these items were primarily manipulative objects, blocks, and transportation toys (traditional, masculine items).

\section{Discussion}

Several of the above findings are noteworthy. The girls' parents' attitudes had much greater predictive value than the boys parents' attitudes, in relation to the actual behavior of the parents. In fact, both parents' views taken together and fathers' views alone, toward boys, were highly predictive of the manner in which the girls" ronms would be decorated. Similarly, both parents' views toward girls had 
a strong predictive value in relation to the style in which the girls' rooms were decorated. Unexpectedly, the boys" parents ${ }^{*}$ views did not demonstrate any significant predictions in their children's rooms.

These results appear to be inconsistent with the parents beliefs regarding who chose the majority of items for the rooms. Most of the girls' parents assert that it was the mothers who primarily decorated the rooms. Yet the girls' fathers' views are highly related to the decorating style. Dne possible explanation, proposed by previous researchers, could be that parents tend to agree on toys' appropriateness to one sex or the other (Schau, Kahn, Diepold, \& Cherry, 1980). So that, even when one parent was designated to create the child's environment, as the mother was in the girls' roams, perhaps there was actually a great deal of influence from the father, and a tendency for both parents to have very similar ideas and desires for the room. Another issue of concern was how many of the homes had the majority of items in the children's rooms. Since both the boys" rooms and the girls' rooms had a similar distribution of items inside or outside of the rooms, this possible confound did not sacm to have an effect at first glance. It should be noted however, that some of the homes with mary items autside of the children's rooms, had a 
higher feminine rating of items in the rooms. This possible effect could be explained by the observance that most of the items left outside of the infants" rooms were those which would have probably been rated as masculine.

In the girls' homes, a higher feminization in the rating occurred in mast of the homes in which many items were outside of the rooms. In the boys' homes, three out of the seven rooms with many items outside, received a negative rating, indicating non-traditional environments (more feminine items selected). This might have been considered a serious confound, especially in the results for the boys" rooms. But the other four boys' homes, with many items outside of the rooms, had more masculine ratings than four of the boys homes with most of the items inside the rooms. Overall, the boys' rooms were rated as somewhat egalitarian in comparison to the ratings of the gifls' rooms.

It is questionable whether this problem may have actually adversely affected the results. If this effect did occur, it could possibly explain the very strong correlations in the girls' rooms in contrast to the lack of correlations in the boys' rooms. In order to eliminate this problem as a possible threat to the internal validity of any future study, it would be advisable to account for the other toys in the hame with which the child interacts. 
Parental Selections

In the home, parents exert influence over their young children's play primarily via their selections of available toys (Block, 1979). Yet, in examining parents' behavior with their two year-olds, Fagot (1987) found different responses to boys and girls, and that the parents were unaware of this differential treatment. In the present study, the parents' attitudes and behaviors toward their daughters appear to match. But the parents of the boys seem to have quite dissimilar views, compared to the style in which they actually decorated their sons" rooms. The boys" rooms were deccrated in somewhat gender-neutral styles. Yet, many of the boys' parents had fairly strong traditional views, as revealed by these questionnaires. Also, most of the boys' parents stated that the fathers participated to some extent in decorating their sons' rooms.

One reason for this discrepancy might be the children's very young age. Many of the decorations in the infant boys" rooms (i.e., lace, bows, hearts, stuffed animals) become less acceptable for boys and deemed more appropriate for girls, with increased age. The gender-sterentype attitude questionnaire referred to many activities that children would engage in at an older age (i.e., run, jump, climb, dress-up). Apparently, the parents of boys are willing to allow a wider range of items in their child's enviranment at 
this young age, which does not necessarily coincide with their actual views toward appropriate gender-related activities for boys.

Evidence has shown that when boys adapt gender-specific choices, they usually interpret them in terms of a narrower scope and greater social value of the male role. Females may adapt masculine behavior with relative impunity, but males who adapt feminine behavior are readily stigmatized. These pressures toward gender-appropriate behavior become stronger fic boys (Muller \& Goldberg). The results of this study indicate an opposite trend for infant boys and girls. A longitudinal study would be advisable to assess how and when the wide scope of acceptable items for the infant boys becomes constrained, and conversely, how and when the narrower range of acceptable items for the infant girls expands. 
Parental Selections

References

Barry, R. J., \& Barry, A. (1976). Stereotyping of sex roles in preschool kindergarten children. Psychological Reports, 38, 948-950.

Bell, N. J. \& Carver, W. (1980). A reevaluation of gender label effects: Expectant mothers' responses to infants. Child Development, 51, 925-927.

Block, J. H. (1979). Another look at sex differentiation in the socialization behaviors of mothers and fathers. In J. Sherman \& F. L. Denmark (Eds.), Psychology of Women: Future of Research. New York: Psychological Dimensions.

Connor, J. M., \& Serbin, L. A. (1977). Behaviorally based masculine and feminine-activity-preference scales for preschoolers: Correlates with other classroom behaviors and cognitive tests. Child Development, $\underline{48}$, 1411-1416.

Fagot, B. I. (1974). Sex differences in toddlers behavior and parental reaction. Developmental Psychology, 10, 554-558.

Fagot, B. I. (1978). The influence of sex of child on parental reactions to toddler children. Child Development, 49, 459-465. 
Parental Selections

Fagot, B. I. (1987). Unraveling the cat's cradle: the problem of gender. Center Review, 6-9.

Fling, 5., \& Manosevitz, M. (1971). Sex-typing in nursery school: Children's play interests. Developmental

Psychology, 1, 146-152.

Miller, C. L. (1987). Qualitative differences among gender-stereotyped toys: Implications for cognitive and social development in girls and boys. Sex Roles, 16, $473-487$.

Muller, R. \& Goldberg, S. (1980). Why William doesn't want a doll: Preschoolers' expectations of adult behavior toward girls and boys. Merrill-Palmer Quarterly, 26, 259-269.

Nadelman, L. (1974). Sex identity in American children: Memory, knowledge, and preference test. Developmental Psychology, 10, 413-417.

Rheingold, H. L., \& Cook, K. V. (1975). The contents of boys' and girls' rooms as an index of parents behavior. Child Development, 46, 459-463. Schau, C. G., Kahn, L., Diepold, J. H., \& Cherry, F. (1980). The relationship of parental expectations and preschool children's verbal sex typing to their sex-typed toy play behavior. Child Development, 51, $607-609$. 
Parental Selections

Seavey, C. A., Katz, P. A., \& Zalk, S. R. (1975). Baby X:

The effect of gender labels on adult responses to infants. Sex Roles, 1, 103-109.

Smith, P. K., \& Dagiish, L. (1977). Sex differences in parent and infant behavior in the home. Child Development, 4 B, $1250-1254$.

Will, J. A., Self, P. A., \& Datan, N. (1976). Maternal behavior and perceived sex of infant. American Journal of Orthopsychiatry, 46, 135-139. 
To: Diane Rose Vincent, Psychology

679 Grand Coulee \#3

Sunnyvale, CA, 94087

From: Charles R. Bolz

office of Graduate studies and Research

Date: March 22, 1990

The Human Subjects Institutional Review Board has approved your request to use human subjects in the study entitled:

"The Influence of sex of Child on Parental Choices for Infant's Room Contents"

This approval is contingent upon the subjects participating in your research project being appropriately protected from risk. This inciucies the protection of the anonymity of the subjects' identity when they participate in your research project, and with regard to any and all data that may be collected from the subjects. The Board's approval includes continued monitoring of your research by the Board to assure that the subjects are being adequately and properly protected from such risks. If at any time a subject becomes injured or complains of injury, you must notify Dr. Serena stanford immediately. Injury includes but is not limited to bodily harm, psychological trauma and release of potentially damaging personal information.

Please also be advised that each subject needs to be fully informed and aware that their participation in your research project is voluntary, and that he or she may withdraw from the project at any time. Further, a subject's participation, refusal to participate or withdrawal will not affect any services the subject is receiving or will receive at the institution in which the research is being conducted.

If you have any questions, please contact Dr. Stanford or me at (408) 924-2480.

cc: Sheila Bienenfeld, Ph.D. 
To: Diane Vincent

$M A$ in Psychology Candidate

FROM: $\quad$ Robert A. Fox MA Coordinator

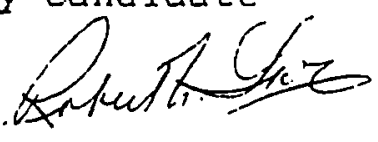

SUBJECT: Thes is Project

This letter is to confirm that you have provided the approval form from the Human subjects Institutional Review Board and have discussed your project with the reviewer who concurs that you may proceed. Consequently, your proposal is approved and you may begin collecting data on the project.

Congratulations on your progress, and good luck with data collection. Please inform me of the method you chose to satisfy the Comprehensive Examination on your thesis. You may do this by committee examination, presentation of findings at a professional meeting or the SPARC Meeting, or publication of your thesis in a refereed journal. If you have any additional questions regarding progress in your program please contact me.

cc: Bienenfield

Pellegrini

Wolfson

Cooper

Nishita 


\section{Appendix B}

\section{Recruitment Script}

"Hello, my name is Diane Vincent. I am a graduate student at San Jose State University working on my Masters degree in Psychology. For my thesis I am studying the bedroom environments of 6-9 month old children. I obtained your name from the record of births. If this is your first child, I would appreciate your permission to observe and photograph the contents of his/ner room, and for you and your spouse to fill out a short questionnaire regarding children's activities. The entire process will involve about an hour of your time. If this is agreeable to you, we can make an appointment at your convenience. Thank you." 
Appendix C

Classification of Items Checki ist

List the total number of each of the following items in the child's room:

1. Blocks

2. Objects to manipulate

3. Transportation toys

4. Male stuffed animals

5. Traditional male designs on furnishings and toys (i.e., sports, aggression, active, animals, vehicles, blue)

6. Female and baby dolls

7. Soft toys and stuffed animals

8. Female stuffed animals

9. Traditional female designs on furnishings and toys (i.e., dance, domestic, passive, hearts, flowers, ruffles, pink)

List the total number of all of the child's items in the room: 


\section{Appendix D}

\section{Activities Questionnaire}

Rate each of the following activities as to the appropriateness for girls:

$0=$ never appropriate, 1 =usually not appropriate, 2=occasionally appropriate, $3=0$ ften appropriate, $4=a 1$ most always appropriate, 5=always appropriate

Manipulating objects Play with transportation toys

Run/Jump/Climb

Play with soft toys/stuffed animals

Dance

Ask for help

Doll play

Block play

Rough and tumble play

Dress-up Help adult

Aggression

Rate each of the following activities as to the appropriateness for boys:

O=never appropriate, 1=usually not appropriate, 2=occasional 1 y appropriate, 3=often appropriate, 4=almost always appropriate, 5=always appropriate

Manipulating objects

Play with transportation toys

Run/Jump/Climb

Play with soft toys/stuffed animals

Dance

Ask for help

Dol l play

Block play

Rough and tumble play

Dress-up

Help adult

Aggrassion

Who chooses the majority of items for your child's bedroom?

(mother) (father) (both) (other) 
Parental Selections

\section{Appendix E}

\section{Detriefing}

The purpose of this study was to determine how parents expectations regarding behavior appropriate for children was expressed in the organization of the children's environments.

It has been hypothesized that parents who maintain traditional attitudes toward boys' and girls' behavior would furnish their children's rooms in a traditional manner. Conversely, it has been expected that parents who have non-traditional attitudes regarding boys' and girls behavior would furnish their children's rooms in a non-traditional style. 